Article

\title{
Phytoestrogen Concentrations in Human Urine as Biomarkers for Dietary Phytoestrogen Intake in Mexican Women
}

\author{
Karina M. Chávez-Suárez ${ }^{1}$, María I. Ortega-Vélez ${ }^{1}$, Ana I. Valenzuela-Quintanar ${ }^{2}$, \\ Marcia Galván-Portillo ${ }^{3}$, Lizbeth López-Carrillo ${ }^{3}$, Julián Esparza-Romero ${ }^{1}$, María S. Saucedo-Tamayo ${ }^{1}$, \\ María R. Robles-Burgueño ${ }^{2}$, Susana A. Palma-Durán ${ }^{2}$ (D), María L. Gutiérrez-Coronado ${ }^{2}$, \\ Melissa M. Campa-Siqueiros ${ }^{1}$, Patricia Grajeda-Cota ${ }^{2}$ and Graciela Caire-Juvera ${ }^{1, *}$ \\ 1 Department of Nutrition, Section of Public Nutrition and Health, Centro de Investigación en Alimentación y \\ Desarrollo, A.C. (CIAD), Carretera a La Victoria km 0.6, 83304 Hermosillo, Sonora, Mexico; \\ kamachasu@gmail.com (K.M.C.-S.); iortega@ciad.mx (M.I.O.-V.); julian@ciad.mx (J.E.-R.); \\ coco@ciad.mx (M.S.S.-T.); melita379@hotmail.com (M.M.C.-S.) \\ 2 Department of Food Sciences, Centro de Investigación en Alimentación y Desarrollo, A.C. (CIAD), \\ Carretera a La Victoria km 0.6, 83304 Hermosillo, Sonora, Mexico; aquintanar@ciad.mx (A.I.V.-Q.); \\ cuquis@ciad.mx (M.R.R.-B.); sussypalmaa@gmail.com (S.A.P.-D.); lulu@ciad.mx (M.L.G.-C.); \\ grajeda@ciad.mx (P.G.-C.) \\ 3 Center for Population Health Research, Instituto Nacional de Salud Pública, Universidad No. 655, \\ Colonia Santa María Ahuacatitlán, Cerrada Los Pinos y Caminera, 62100 Cuernavaca, Morelos, Mexico; \\ mgalvan@insp.mx (M.G.-P.); lizbeth@insp.mx (L.L.-C.) \\ * Correspondence: gcaire@ciad.mx; Tel.: +52-662-289-2400 (ext. 395)
}

Received: 15 August 2017; Accepted: 13 September 2017; Published: 29 September 2017

\begin{abstract}
There has been substantial interest in phytoestrogens, because of their potential effect in reducing cancer and heart disease risk. Measuring concentrations of phytoestrogens in urine is an alternative method for conducting epidemiological studies. Our objective was to evaluate the urinary excretion of phytoestrogens as biomarkers for dietary phytoestrogen intake in Mexican women. Participants were 100 healthy women from 25 to 80 years of age. A food frequency questionnaire (FFQ) and a $24 \mathrm{~h}$ recall were used to estimate habitual and recent intakes of isoflavones, lignans, flavonols, coumestrol, resveratrol, naringenin, and luteolin. Urinary concentrations were measured by liquid chromatography (HPLC) coupled to mass spectrometry (MS) using the electrospray ionization interface (ESI) and diode array detector (DAD) (HPLC-DAD-ESI-MS). Spearman correlation coefficients were used to evaluate associations between dietary intake and urine concentrations. The habitual consumption (FFQ) of total phytoestrogens was $37.56 \mathrm{mg} /$ day. In urine, the higher compounds were naringenin $(60.1 \mu \mathrm{g} / \mathrm{L})$ and enterolactone $(41.7 \mu \mathrm{g} / \mathrm{L})$. Recent intakes $(24 \mathrm{~h}$ recall) of isoflavones $(r=0.460, p<0.001)$, lignans $(r=0.550, p<0.0001)$, flavonoids $(r=0.240, p<0.05)$, and total phytoestrogens $(r=0.410, p<0.001)$ were correlated to their urinary levels. Total phytoestrogen intakes estimated by the FFQ showed higher correlations to urinary levels $(r=0.730, p<0.0001)$. Urinary phytoestrogens may be useful as biomarkers of phytoestrogen intake, and as a tool for evaluating the relationship of intake and disease risk in Mexican women.
\end{abstract}

Keywords: phytoestrogen intake; urinary excretion; biomarker; Mexican women

\section{Introduction}

Experimental evidence suggests that phytoestrogen intake may modulate the risk of cancer and cardiovascular disease [1-4]. Phytoestrogens are plant-derived, naturally occurring non-steroidal polycyclic phenols that may have weak estrogenic effects when they are ingested and metabolized [5]. 
Major classes of phytoestrogens are isoflavones, lignans, and coumestans. Diet is the main source of phytoestrogens in humans. Isoflavones are present in berries, soybeans, and other legumes [6]. Lignans, primarily matairesinol and secoisolariciresinol, are found widely in many fiber rich foods such as fruits, vegetables, cereals, and flaxseeds [7]. The main dietary sources of coumestans are alfalfa sprouts, followed by pinto and pea beans [8]. Resveratrol, from the stilbene group, is found in wine, grape skins, and peanuts [9].

The estimation of dietary consumption of phytoestrogens is limited by the scarcity of data on the content of food; therefore, food composition databases are complex to establish. Phytoestrogen analysis in food is complicated due to the variety of matrices and the different concentrations in foods. Thus, there is a need for a validated biomarker of phytoestrogen intake for epidemiological studies [10]. An alternative approach for determining the intake of phytoestrogens, is measuring them in biological samples, such as urine.

Phytoestrogens in food are mainly in the form of several types of conjugates ( $\beta$-glycosidic) and in smaller amounts as aglycones. Conjugate forms (inactive) are ingested and hydrolyzed to their aglycone forms (bioactive) by bacterial $\beta$-glucosidases in the intestine wall. Then, only the bioactive forms are absorbed by the intestinal tract, and can be further glucuronidated in the intestinal wall and liver [11]. Overall, the main circulating and excreting forms of phytoestrogens are the glucuronidated metabolites. Urinary excretion of phytoestrogens varies with the type of diet, which may be related to differences in both human pharmacokinetics and metabolism by the intestinal bacteria [12].

At population level, little information is available on the excretion of urinary phytoestrogens and their associations with dietary intakes in Western countries. Dietary intake of phytoestrogens has been associated with urinary excretion of related metabolites in observational studies [1,13-15] and controlled trials [16,17]. In Mexico, a study evaluated the phytoestrogens consumption in typical diets [18]; however, a main limitation was the scarcity of foods with phytoestrogen concentrations in food composition databases. We have previously evaluated phytoestrogens in serum as biomarkers of intake in Mexican women, although limited correlations for individual compounds were found [19]. Furthermore, there are no studies on the concentration of urinary phytoestrogens of the general population. Therefore, the ability to monitor objectively exposure to these compounds is important in order to understand the health impact of dietary intake of phytoestrogens in Mexican population. A better understanding of the relationship of phytoestrogen consumption and urine concentration in the population of Mexico is essential for carrying out epidemiological research regarding the association between phytoestrogens and health.

Therefore, the aim of this study was to determine phytoestrogens in urine as biomarkers of phytoestrogen intake, by measuring the association of urinary excretion of these compounds with recent and habitual dietary intakes in Mexican women. Estimates of dietary intakes of isoflavones (genistein, daidzein, equol, glycitein, formononetin, biochanin A), lignans (enterodiol, enterolactone, secoisolariciresinol, matairesinol), flavonols (quercetin, kaempferol), flavanones (naringenin), flavones (luteolin), stilbenes (resveratrol), and coumestans (coumestrol) were compared with their urinary compounds.

\section{Materials and Methods}

\subsection{Study Subjects}

Subjects in this cross-sectional study were 100 apparently healthy women, aged 25 to 80 years and with at least 5 years of residence in Northwest México. Women were excluded from the study if they were pregnant or breastfeeding, or have had prior diagnosis of specific chronic illnesses such as diabetes, cancer, or heart disease. Participants were selected randomly from 20 blocks in the city of Hermosillo, Sonora, Mexico, through the Master Sample Frame, which is the basis sample of houses for the surveys that make up the System of National Health Surveys in México. 
The protocol for this research was reviewed and approved by the Ethical Committee from Centro de Investigación en Alimentación y Desarrollo (Center for Research on Food and Development). The investigation was carried out following the Declaration of Helsinki; all women provided written informed consent prior to participation. Socioeconomic and demographic indicators were collected at first interview in women's households. Weight and height were measured using standardized procedures to characterize the study population. Weight was measured by a portable electronic scale (and FG-150KBM (up to $150 \mathrm{~kg}$ weighing capacity) with $0.05 \mathrm{~kg}$ of accuracy). Height was measured using a portable stadiometer (SECA). Body mass index was calculated from weight and height.

\subsection{Dietary Assessment}

Habitual intake of phytoestrogens was assessed using a food frequency questionnaire (FFQ) validated for women in the region [20] and modified for this study. The questionnaire was applied by trained interviewers, and included 162 food items from 11 categories. Frequency of consumption of each food item was evaluated on a daily, weekly, or monthly basis, and portion sizes (small, medium, large) were specified.

Recent intake of phytoestrogens was assessed using a $24 \mathrm{~h}$ dietary recall on the same day that the urine sample was taken. Printed food models, plates, glasses and spoons were used as visual aids to improve recall. Additionally, a second $24 \mathrm{~h}$ dietary recall was applied to a subsample of 50 women, with a minimum of three weeks between interviews, to calculate the coefficient of intraindividual variation of daily intake.

Quantification of daily intakes of 16 phytoestrogens considered in this study was performed using a food dictionary that included data from the USDA [6], the National Institute of Nutrition in Mexico, and the food composition database from our Institute. In addition, tables and databases from different studies [7-9,21-24] were used to identify foods that are a source of phytoestrogens. Total phytoestrogen intake was calculated as the sum of lignans, isoflavones, flavonoids, coumestrol and resveratrol intakes.

\subsection{Urine Collection}

Subjects were provided with supplies and instructed in the total collection of $12 \mathrm{~h}$ urine on any day but those of the menstrual period. Participants should not have consumed any antibiotics or other kind of drugs within 7 days prior to urine collection. Total $12 \mathrm{~h}$ urine was collected in $0.5 \mathrm{~L}$ portable containers with $0.5 \mathrm{~g}$ of L-ascorbic acid (A4544-100G, Sigma-Aldrich, St. Louis, MO, USA), to prevent microbial contamination and oxidative degradation [25]. Subjects were asked to use a separate container for before-dinner urine, overnight urine, and the first urine excreted in the morning of the following day, and to store containers in their refrigerators at $4-6{ }^{\circ} \mathrm{C}$ or cooler until the next morning. Total $12 \mathrm{~h}$ urine samples were picked up and transported in a cooler to the laboratory. The total urine volume of each subject was measured, and a sample was filtered using Whatman grade 41 filters. The filtered samples were dispensed into $5 \mathrm{~mL}$ aliquots and stored in polypropylene cryogenic vials at $-70{ }^{\circ} \mathrm{C}$ until analysis of phytoestrogens. One aliquot was sent to a biomedical laboratory for analysis of urinary creatinine.

\subsection{Urine Analysis}

Urine samples $(n=100)$ were analyzed for phytoestrogens using liquid-liquid extraction (LLE) based on a protocol published by Bolca et al. [26], followed by a high-resolution chromatography-mass spectrometry (HPLC-MS) analysis using the method described by Wyns et al. [27], previously modified for the analysis of phytoestrogens using HPLC-DAD-ESI-mass spectrometry. Urine samples were analyzed for total concentration of isoflavones (genistein, daidzein, equol, glicitein, formononetin, biochanine A), lignans (enterodiol, enterolactone, secoisolariciresinol, matairesinol), coumestans (coumestrol), stilbenes (resveratrol), flavonols (quercetin, kaempferol), flavanones (naringenin), and flavones (luteolin). Quercetin, luteolin, and naringenin were obtained from Indofine Chemical (Hillsborough, NJ, USA). The remaining phytoestrogens, the internal standard 
(4-hydroxybenzophenone), deconjugation internal standards ( $\beta$-phenolphthalein glucuronide and 4-methylumbelliferone sulfate), and Helix pomatia, H1, were obtained from Sigma-Aldrich.

Prior to extraction, urine samples were centrifuged at $3000 \mathrm{rpm}$ for $10 \mathrm{~min}$ to remove solids and $2.0 \mathrm{~mL}$ of supernatant were diluted with $2.0 \mathrm{~mL}$ of sodium acetate buffer $(\mathrm{pH} 5.0 ; 0.1 \mathrm{M})$, spiked with $100 \mu \mathrm{L}$ of internal standard 4-hydroxybenzophenone $(4 \mu \mathrm{g} / \mathrm{mL})$ and $10 \mu \mathrm{L}$ of deconjugation internal standards $(20 \mu \mathrm{g} / \mathrm{mL})$. Conjugated analytes were hydrolyzed by the addition of $30 \mu \mathrm{L}$ $\beta$-glucuronidase/sulfatase (Helix pomatia, H1, containing $5.14 \mathrm{mg}$ of enzyme in $1 \mathrm{~mL}$ of sodium acetate buffer, $\mathrm{pH} 5.0,0.1 \mathrm{M}$ ) and incubated $4 \mathrm{~h}$ at $37^{\circ} \mathrm{C}$. Urine-deconjugated samples were extracted (twice) with $5 \mathrm{~mL}$ of diethyl ether and subsequent vortex mixing (30 s). After samples stand for $5 \mathrm{~min}$, the organic phase, containing phytoestrogens, was transferred into a new $15 \mathrm{~mL}$ conical tube. Eluates collected were dried under a gentle nitrogen stream, dissolved in a $200 \mu \mathrm{L}$ injection solvent $(40 / 60$, $v / v$ ) (initial mobile phase (65A:35B) and methanol) with a gentle vortexing for $1 \mathrm{~min}$ and transferred into an amber vial for HPLC-DAD-ESI analysis. The phytoestrogens in the extracted samples were separated by injecting $50 \mu \mathrm{L}$ of filtered extract into the Agilent 1100 series HPLC system (Agilent Technologies Inc., Palo Alto, CA, USA).

HPLC analyses were carried out using a Waters XBridge C18 reversed phase $(3.5 \mu \mathrm{m})$ column $(3.0 \mathrm{~mm}$ internal diameter $\times 150 \mathrm{~mm})$ connected to a $\mathrm{C} 18$ guard column $(3.0 \mathrm{~mm}$ internal diameter $\times 20 \mathrm{~mm}$ ) and maintained at a temperature of $52^{\circ} \mathrm{C}$. The mobile phase was milliQ $\mathrm{H}_{2} \mathrm{O}$ (Solvent $\mathrm{A}$ ) and $\mathrm{MeOH} / \mathrm{CH}_{3} \mathrm{CN}(80 / 20, w / w)$ (Solvent B), both acidified with $0.025 \%(v / v)$ formic acid. The gradient and flow rate were programmed as follows: $0-5.0 \mathrm{~min}$ : 35-40\% B (flow: $0.6 \mathrm{~mL} / \mathrm{min}$ ), $5.0-16.0 \mathrm{~min}$ : 40-100\% B (flow: $0.6 \mathrm{~mL} / \mathrm{min}$ ), $16.0-19.0 \mathrm{~min}$ : isocratic 100\% B (flow. $0.8 \mathrm{~mL} / \mathrm{min}$ ), $19.0-19.1 \mathrm{~min}$ : 100-35\% B (flow: $0.6 \mathrm{~mL} / \mathrm{min}$ ) and $2.9 \mathrm{~min}$ for re-equilibration of the column before subsequent injection. Analyses were monitored simultaneously by diode array detection at 260, 280, 290, 310, and $360 \mathrm{~nm}$ during the entire HPLC run. All sample compounds were ionized by electrospray (ESI) in the negative ion mode and analyzed by single quadrupole mass spectrometry for confirmation of phytoestrogens. The drying temperature was $350^{\circ} \mathrm{C}$. The nebulizer pressure was $60 \mathrm{psi}$, the capillary voltage $3.5 \mathrm{kV}$, and the drying gas flow $11 \mathrm{~L} / \mathrm{min}$. Quality control samples (spiked urine) were analyzed along with unknown samples.

Linearity of the method $\left(r^{2}=0.995-0.999\right)$ was established using eight different concentrations covering from 0.16 to $2400 \mathrm{ng} / \mathrm{mL}$. The limit of detection was from 0.001 to $0.075 \mathrm{ng} / \mathrm{mL}$. In addition, different blanks were run to exclude the presence of interferences and ensure the results. The recovery of phytoestrogens was from 80 to $120 \%$, with the exception of resveratrol (50\%) and secoisolarisiresinol $(60 \%)$.

\subsection{Statistical Analysis}

Urinary concentrations of phytoestrogens are expressed as micrograms of phytoestrogens per gram of urinary creatinine $(\mu \mathrm{g} / \mathrm{g})$ by adjusting concentrations for urinary creatinine levels [26]. The mean dietary nutrient intake was adjusted for total energy intake using the residual method [28]. Spearman rank correlations were used to assess the relationship of habitual and recent intake of total phytoestrogens and subgroups with urinary phytoestrogen excretion. The raw correlation was first evaluated and then attenuated considering intraindividual variation in daily consumption of food. Statistical analyses were performed using the STATA statistical software package, version 8.0 (StataCorp LP, College Station, TX, USA). Statistical significance was assumed at the level of 0.05.

\section{Results}

\subsection{General Characteristics of Participants}

Mean age of the women was $44.7 \pm 12.7$ years. The majority of women were premenopausal $(57 \%)$, married $(74 \%)$, and of low socioeconomic status (62\%). Overall, the prevalence of overweight and obesity according to body mass index was $79 \%$. When nutrient intakes were estimated by the $24 \mathrm{~h}$ recall, mean energy intake was $1473 \mathrm{kcal} /$ day, and, by the FFQ, energy intake was $2563 \mathrm{kcal} /$ day. 


\subsection{Intake of Phytoestrogens}

There was a wide variation in intake among phytoestrogen groups, values were right-skewed. The mean and geometric mean of phytoestrogens intake estimated by the FFQ are shown in Tables 1 and 2. Intakes of naringenin, quercetin, and coumestrol were the highest. The more consumed isoflavone was genistein, followed by daidzein. On the other hand, estimation of phytoestrogen intakes using the $24 \mathrm{~h}$ recall (Tables 3 and 4 ) showed that naringenin, quercetin, and genistein were the most consumed phytoestrogens. Recent intake of coumestrol ( $403 \mu \mathrm{g} /$ day) was lower than its estimated habitual intake $(1850 \mu \mathrm{g} /$ day). In general, estimated recent intakes of phytoestrogens were lower than habitual intakes.

\subsection{Phytoestrogens in Urine}

Urine volumes ranged from 0.22 to $1.7 \mathrm{~L}$, and the mean concentration of creatinine was $0.63 \mathrm{~g} / \mathrm{L}$. The majority of phytoestrogens $(75 \%)$ were detected in $77 \%$ of the urine samples analyzed. Table 5 shows that, from the group of isoflavones, biochanin A and daidzein had respectively the lowest and highest concentrations in urine. From the group of lignans, enterolactone was the more detected phytoestrogen in urine, and the lower concentration was found for matairesinol, which is metabolized to enterolactone. In the flavonoid group, naringenin in urine was 40 times higher than quercetin.

Table 1. Isoflavone, coumestrol, and resveratrol intakes estimated by the FFQ in Mexican women $(n=100)$.

\begin{tabular}{ccccccc}
\hline Phytoestrogens & \multirow{2}{*}{ Mean \pm SD } & Geometric Mean * & Value & \multicolumn{3}{c}{ Percentiles } \\
\cline { 1 - 4 }$(\mu$ g/Day) & & $\mathbf{9 5 \%} \mathbf{C I})$ & Min-Max & $\mathbf{2 5}$ & $\mathbf{5 0}$ & $\mathbf{7 5}$ \\
\hline Daidzein & $1151 \pm 3211$ & $388.5(283-533)$ & $30.7-26,249$ & 145.8 & 232.5 & 867.9 \\
Genistein & $1642 \pm 5251$ & $642(452-912)$ & $38.0-46,147$ & 156.0 & 296.0 & 1023.7 \\
Glicitein & $14.8 \pm 16.9$ & $11.3(9.5-13.4)$ & $2.6-107.3$ & 7.3 & 10.4 & 15.3 \\
Biochanin A & $310 \pm 279$ & $270.5(236-310)$ & $23.7-1420.6$ & 105.9 & 234.8 & 471.5 \\
Formononetin & $53.0 \pm 110.2$ & $28.3(22.6-35.5)$ & $1.6-775.7$ & 14.2 & 23.9 & 42.1 \\
Equol & $2.4 \pm 1.9$ & $1.9(1.6-2.2)$ & $0.2-13.6$ & 1.1 & 1.9 & 3.16 \\
Total isoflavones & $3173 \pm 8456$ & $1168(894-1526)$ & $289-73,037$ & 625.8 & 1025.4 & 2297.8 \\
Coumestrol & $1850 \pm 1730$ & $1569(1333-1847)$ & $96.6-8633.7$ & 541.9 & 1361.3 & 2901 \\
Resveratrol & $17.4 \pm 43.7$ & $5.2(3.6-7.4)$ & $0.006-290.3$ & 0.9 & 4.4 & 14.8 \\
\hline
\end{tabular}

FFQ: Food Frequency Questionnaire; SD: Standard Deviation; 95\% CI: 95\% Confidence Interval; * Adjusted for energy intake by the residual method [25]. Total isoflavones consist of the sum of daidzein, genistein, glicitein, biochanin A, formononetin, and equol.

Table 2. Lignan, flavonoid, and total phytoestrogen intakes estimated by the FFQ in Mexican women $(n=100)$.

\begin{tabular}{|c|c|c|c|c|c|c|}
\hline \multirow{2}{*}{$\begin{array}{c}\text { Phytoestrogens } \\
\text { ( } \mu \mathrm{g} / \text { Day })\end{array}$} & \multirow{2}{*}{ Mean \pm SD } & \multirow{2}{*}{$\begin{array}{c}\text { Geometric Mean * } \\
(95 \% \mathrm{CI})\end{array}$} & \multirow{2}{*}{$\begin{array}{c}\text { Value } \\
\text { Min-Max }\end{array}$} & \multicolumn{3}{|c|}{ Percentiles } \\
\hline & & & & 25 & 50 & 75 \\
\hline Secoisolariciresinol & $712.8 \pm 1448$ & $490.5(386-623)$ & $69.6-11,771$ & 145.6 & 222.5 & 586.9 \\
\hline Matairesinol & $20.1 \pm 14.0$ & 17.1(15.3-19.1) & $3.9-97.3$ & 11.4 & 17.2 & 25.1 \\
\hline Enterodiol & $67.4 \pm 37.6$ & $62.5(57.2-68.3)$ & $16.4-222.3$ & 42.3 & 61.8 & 80.9 \\
\hline Enterolactone & $183.2 \pm 115.2$ & $156.7(138-178)$ & $49.9-662.7$ & 102.2 & 158.9 & 227.6 \\
\hline Total lignans & $1171 \pm 1586$ & 872.7 (742-1027) & $240.9-13,335$ & 439.9 & 754.9 & 1182.3 \\
\hline Naringenin & $15,940 \pm 16,582$ & $12,429(10,243-15,082)$ & $737.2-111,747$ & 4887.4 & 10,997 & 20,759 \\
\hline Luteolin & $1555 \pm 1355$ & $1239(1065-1441)$ & $143.9-8772.0$ & 670.2 & 1221.0 & 2019.4 \\
\hline Kaempferol & $826.1 \pm 685.4$ & $625.5(538-728)$ & $120.0-4519.6$ & 351.1 & 649.6 & 1018.3 \\
\hline Quercetin & $13,023 \pm 6912$ & $11,353(10,129-12,724)$ & $1719.3-31,993$ & 7873.9 & 11,472 & 17,865 \\
\hline Total flavonoids & $31,344 \pm 20,862$ & $26,773(23,600-30,373)$ & $6527-139,335$ & 15,617 & 28,101 & 39,288 \\
\hline Total phytoestrogens & $37,557 \pm 23,909$ & $31,957(28,322-36,059)$ & $9016-159,239$ & 20,716 & 32,716 & 48,554 \\
\hline
\end{tabular}

FFQ: Food Frequency Questionnaire; SD: Standard Deviation; 95\% CI: 95\% Confidence Interval; * Adjusted for energy intake by the residual method [25]. Total lignans consist of the sum of secosiolariciresinol, matairesinol, enterodiol, and enterolactone. Total flavonoids consist of the sum of naringenin, luteolin, kaempferol, and quercetin. Total phytoestrogens consist of the sum of isoflavones, lignans, coumestrol, flavonoids, and resveratrol. 
Table 3. Isoflavone, coumestrol, and resveratrol intakes estimated by the $24 \mathrm{~h}$ recall in Mexican women $(n=100)$.

\begin{tabular}{ccccccc}
\hline \multirow{2}{*}{ Phytoestrogens } & \multirow{2}{*}{ Mean $\pm \mathbf{S D}$} & Geometric Mean * & Value & \multicolumn{3}{c}{ Percentiles } \\
\cline { 1 - 5 } $\boldsymbol{n n n y y y n}(\boldsymbol{\mu g} /$ Day) & & $\mathbf{9 5 \%} \mathbf{C I})$ & Min-Max & $\mathbf{2 5}$ & $\mathbf{5 0}$ & $\mathbf{7 5}$ \\
\hline Daidzein & $517 \pm 2234$ & $214(157-289)$ & $0.67-16,220$ & 22.5 & 86.4 & 135.7 \\
Genistein & $775 \pm 3508$ & $262(184-375)$ & $0.58-26,450$ & 24.17 & 70.1 & 173.8 \\
Glicitein & $9.46 \pm 9.81$ & $6.14(5.06-7.45)$ & $0.485-57.9$ & 3.01 & 5.24 & 14.7 \\
Biochanin A & $57.9 \pm 81.1$ & $37.8(29.0-49.2)$ & $0.02-520$ & 4.62 & 29.9 & 76.4 \\
Formononetin & $19.8 \pm 25.6$ & $14.2(10.8-18.6)$ & $0-159.4$ & 1.38 & 4.28 & 31.3 \\
Equol & $1.13 \pm 1.52$ & $0.67(0.49-0.92)$ & $0-6.55$ & 0 & 0.44 & 1.66 \\
Total isoflavones & $1380 \pm 5710$ & $567(423-761)$ & $3.3-40,789$ & 116.5 & 271.6 & 441.5 \\
Coumestrol & $403 \pm 1255$ & $186(132-264)$ & $0.09-11,643$ & 1.41 & 3.65 & 433.4 \\
Resveratrol & $2.13 \pm 21.1$ & $2.91(2.15-3.94)$ & $0-211.2$ & 0 & 0 & 0 \\
\hline
\end{tabular}

SD: Standard Deviation; 95\% CI: 95\% Confidence Interval; * Adjusted for energy intake by the residual method [25]. Total isoflavones consist of the sum of daidzein, genistein, glicitein, biochanin A, formononetin, and equol.

Table 4. Lignan, flavonoid, and total phytoestrogen intakes estimated by the $24 \mathrm{~h}$ recall in Mexican women $(n=100)$.

\begin{tabular}{ccccccc}
\hline Phytoestrogens & \multirow{2}{*}{ Mean \pm SD } & Geometric Mean & Value & \multicolumn{3}{c}{ Percentiles } \\
\cline { 4 - 6 }$(\boldsymbol{\mu}$ /Day) & & $\mathbf{( 9 5 \%} \mathbf{C I})$ & Min-Max & $\mathbf{2 5}$ & $\mathbf{5 0}$ & $\mathbf{7 5}$ \\
\hline Secoisolariciresinol & $307 \pm 1767$ & $65.7(50.0-86.4)$ & $9.12-16,938$ & 31.83 & 52.2 & 81.3 \\
Matairesinol & $16.0 \pm 45.2$ & $9.61(7.83-11.8)$ & $0.58-438$ & 4.14 & 7.24 & 13.9 \\
Enterodiol & $18.7 \pm 23.0$ & $15.2(12.5-18.5)$ & $0-133.6$ & 1.99 & 11.6 & 26.3 \\
Enterolactone & $67.6 \pm 83.4$ & $53.4(42.9-66.4)$ & $0-435.5$ & 8.59 & 41.7 & 88.7 \\
Total lignans & $409.1 \pm 1781$ & $162.4(130-204)$ & $15.6-17,001$ & 75.0 & 130 & 212 \\
Naringenin & $5352 \pm 18,834$ & $1356(901-2040)$ & $0-151,179$ & 0 & 196 & 1191 \\
Luteolin & $471 \pm 1081$ & $157(108-228)$ & $0-6379.3$ & 5.77 & 46.5 & 330.8 \\
Kaempferol & $476 \pm 1274$ & $327(247-434)$ & $0-8224.2$ & 29.94 & 116.9 & 255.9 \\
Quercetin & $8170 \pm 8954$ & $5202(4090-6616)$ & $0-56,088$ & 1514 & 5851 & 11,277 \\
Total flavonoids & $14,471 \pm 21,693$ & $8432(6578-10,807)$ & $0-160,534$ & 2775 & 8467 & 18,208 \\
Total Phytoestrogens & $16,663 \pm 22,858$ & $10,838(8757-13,414)$ & $54-161,360$ & 3591 & 9842 & 20,258 \\
\hline
\end{tabular}

SD: Standard Deviation; 95\% CI: 95\% Confidence Interval; ${ }^{*}$ Adjusted for energy intake by the residual method [25]. Total lignans consist of the sum of secosiolariciresinol, matairesinol, enterodiol, and enterolactone. Total flavonoids consist of the sum of naringenin, luteolin, kaempferol, and quercetin. Total phytoestrogens consist of the sum of isoflavones, lignans, coumestrol, flavonoids, and resveratrol.

Table 5. Urinary concentrations of phytoestrogens during 12-h urine collection period $(n=100)$.

\begin{tabular}{|c|c|c|c|c|c|c|}
\hline \multirow{2}{*}{$\begin{array}{c}\text { Phytoestrogens } \\
(\mu \mathrm{g} / \mathrm{L})\end{array}$} & \multirow{2}{*}{ Mean \pm SD } & \multirow{2}{*}{$\frac{\text { Geometric Mean * }}{(95 \% \mathrm{CI})}$} & \multicolumn{3}{|c|}{ Percentiles } & \multirow{2}{*}{$\begin{array}{c}\text { Geometric Mean * } \\
\mu g / g \text { Creatinin }(95 \% \text { CI })\end{array}$} \\
\hline & & & 25 & 50 & 75 & \\
\hline Daidzein & $117 \pm 236$ & $31.2(21.9-44.4)$ & 10.9 & 38.1 & 103 & $56.0(39.7-79.1)$ \\
\hline Genistein & $49.2 \pm 101$ & $17.4(12.5-24.1)$ & 4.62 & 18.4 & 48.8 & $30.9(22.6-42.5)$ \\
\hline Glicitein & $34.5 \pm 88.3$ & $25.5(16.6-39.4)$ & 0 & 0 & 25.8 & $43.5(28.7-66.1)$ \\
\hline Biochanin A & $1.25 \pm 1.04$ & $1.02(0.89-1.17)$ & 0.68 & 1.08 & 1.50 & $1.86(1.59-2.18)$ \\
\hline Formononetin & $2.42 \pm 1.71$ & $2.31(2.05-2.61)$ & 1.49 & 2.16 & 3.28 & $4.19(3.72-4.72)$ \\
\hline Equol & $42.4 \pm 120$ & $29.9(25.3-35.5)$ & 14.2 & 23.1 & 40.3 & $51.2(44.0-59.4)$ \\
\hline Secoisolariciresinol & $3.45 \pm 5.73$ & $2.89(2.36-3.55)$ & 0.69 & 1.91 & 5.13 & $5.49(4.39-6.86)$ \\
\hline Matairesinol & $0.64 \pm 2.07$ & $1.10(0.63-1.90)$ & 0 & 0 & 0.11 & $1.82(1.01-3.26)$ \\
\hline Enterodiol & $2.86 \pm 12.9$ & 10.5 (5.93-18.7) & 0 & 0 & 0 & 19.7 (11.9-32.6) \\
\hline Enterolactone & $64.9 \pm 66.8$ & 41.7 (33.5-51.9) & 24.8 & 46.7 & 82.3 & 75.9 (59.8-96.4) \\
\hline Coumestrol & $1.24 \pm 1.09$ & $1.10(0.91-1.33)$ & 0.55 & 1.01 & 1.72 & $2.07(1.71-2.50)$ \\
\hline Resveratrol & $11.9 \pm 108$ & $1.32(0.89-1.96)$ & 0 & 0.23 & 1.72 & $2.51(1.69-3.73)$ \\
\hline Luteolin & $6.72 \pm 32.5$ & $2.57(2.12-3.10)$ & 1.40 & 2.38 & 4.31 & $4.61(3.85-5.53)$ \\
\hline Kaempferol & $25.8 \pm 54.9$ & $12.9(9.67-17.4)$ & 2.13 & 10.4 & 26.1 & $22.9(17.2-30.8)$ \\
\hline Naringenin & $135 \pm 213$ & $60.1(46.3-78.1)$ & 26.2 & 64.8 & 127 & $108(83.2-140)$ \\
\hline Quercetin & $2.96 \pm 7.14$ & $2.15(1.77-2.60)$ & 0.71 & 1.83 & 3.34 & $3.92(3.25-4.73)$ \\
\hline Total Phytoestrogens & $502 \pm 580$ & $336(284-398)$ & 213 & 306 & 5175 & $603(511-713)$ \\
\hline
\end{tabular}

SD: Standard Deviation; 95\% CI: 95\% Confidence Interval; ${ }^{*}$ Adjusted for energy intake by the residual method [25]. Total phytoestrogens consist of the sum of total isoflavones, total lignans, coumestrol, total flavonoids, and resveratrol. 


\subsection{Correlations of Dietary and Urinary Phytoestrogens}

The corrected correlation coefficients between phytoestrogen intakes estimated by the FFQ and by the $24 \mathrm{~h}$ recall and their concentrations in urine are shown in Table 6. Using the FFQ, only dietary and urinary resveratrol were correlated $(r=0.337, p<0.01)$. Although at the individual level correlations were not found between habitual dietary intakes (FFQ) and urine concentrations, total phytoestrogens showed a high correlation $(r=0.730, p<0.001)$ between FFQ and urine excretion. On the other hand, recent intakes (24 h recall) of genistein $(r=0.374, p<0.01)$, and naringenin $(r=0.620, p<0.0001)$ were correlated with their respective urinary levels. As a group, recent consumptions ( $24 \mathrm{~h}$ recall) of isoflavones $(r=0.460, p<0.001)$, lignans $(r=0.550, p<0.0001)$, flavonoids $(r=0.240, p<0.05)$, and total phytoestrogens $(r=0.410, p<0.001)$ correlated with their urinary excretion.

Enterodiol and matairesinol were detected in only $15 \%$ and $26 \%$ of the urine samples. Spearman's correlation coefficient between urinary daidzein concentration and its metabolite equol was $0.30(p=0.002)$. Additionally, urinary secoisolariciresinol concentration was correlated with its metabolite enterodiol $(r=0.23 ; p=0.019)$.

Table 6. Corrected correlation coefficients between urinary metabolites and dietary estimates of phytoestrogen intake (Habitual-FFQ and Recent-24 h recall).

\begin{tabular}{|c|c|c|c|c|}
\hline \multirow[b]{2}{*}{ Phytoestrogen } & Corr CC & \multirow[b]{2}{*}{$p$-Value } & \multirow{2}{*}{$\begin{array}{c}\text { Corr CC } \\
\text { Recent ( } \mu g / \text { Day) vs. } \\
\text { Urine }(\mu g / g \text { Creatinine) }\end{array}$} & \multirow[b]{2}{*}{$p$-Value } \\
\hline & $\begin{array}{l}\text { Habitual ( } \mu g / \text { Day) vs. } \\
\text { Urine ( } \mu g / g \text { Creatinine) }\end{array}$ & & & \\
\hline Daidzein & -0.024 & 0.840 & 0.099 & 0.420 \\
\hline Genistein & -0.034 & 0.784 & 0.374 & 0.002 \\
\hline Equol & 0.126 & 0.283 & 0.079 & 0.500 \\
\hline Glicitein & 0.055 & 0.657 & 0.120 & 0.330 \\
\hline Biochanin A & 0.012 & 0.923 & 0.160 & 0.190 \\
\hline Formononetin & -0.024 & 0.841 & 0.170 & 0.160 \\
\hline Total Isoflavones & 0.002 & 0.983 & 0.460 & 0.0001 \\
\hline Secoisolariciresinol & 0.009 & 0.934 & 0.230 & 0.060 \\
\hline Matairesinol & 0.079 & 0.524 & 0.028 & 0.810 \\
\hline Enterolactone & -0.035 & 0.775 & 0.067 & 0.580 \\
\hline Enterodiol & -0.168 & 0.171 & 0.130 & 0.270 \\
\hline Total lignans & -0.111 & 0.359 & 0.550 & 0.000 \\
\hline Naringenin & 0.069 & 0.571 & 0.620 & 0.000 \\
\hline Luteolin & -0.104 & 0.398 & -0.200 & 0.090 \\
\hline Kaempferol & -0.084 & 0.496 & 0.040 & 0.690 \\
\hline Quercetin & 0.154 & 0.212 & 0.027 & 0.820 \\
\hline Total Flavonoids & 0.055 & 0.653 & 0.240 & 0.043 \\
\hline Coumestrol & -0.035 & 0.800 & 0.120 & 0.320 \\
\hline Resveratrol & 0.337 & 0.005 & 0.005 & 0.960 \\
\hline Total Phytoestrogens & 0.730 & 0.000 & 0.410 & 0.0007 \\
\hline
\end{tabular}

FFQ: Food Frequency Questionnaire; Corr CC: Corrected correlation coefficient for intra-interindividual variation. Total isoflavones consist of the sum of daidzein, genistein, glicitein, biochanin A, formononetin, and equol. Total lignans consist of the sum of secosiolariciresinol, matairesinol, enterodiol, and enterolactone. Total flavonoids consist of the sum of naringenin, luteolin, kaempferol, and quercetin. Total phytoestrogens consist of the sum of isoflavones, lignans, coumestrol, flavonoids, and resveratrol.

\section{Discussion}

In this study, we estimated habitual and recent dietary intakes of phytoestrogens, and measured the urinary excretion of these compounds and related metabolites in a group of Mexican adult women. We also evaluated the relationship between dietary and urinary phytoestrogens and observed that total dietary phytoestrogens, estimated by the FFQ, correlated to their urinary excretion. When we estimated dietary intake of phytoestrogens using the $24 \mathrm{~h}$ dietary recall, more correlations between dietary and urinary phytoestrogens were found, including genistein, naringenin, isoflavones, lignans, flavonoids, and total phytoestrogens.

Total phytoestrogens in our study included 16 individual compounds. No observational studies have examined simultaneously a wide range of phytoestrogens. The degree of correlation observed 
between total urinary phytoestrogens and our estimates of dietary intake were in the magnitude of 0.73 (corrected) for the FFQ, and 0.41 (corrected) for the $24 \mathrm{~h}$ recall. Correlations for the FFQ are higher than those obtained in previous study where the correlation between total dietary intake and urinary phytoestrogens was 0.54 [29]. As observed, we obtained a higher correlation of total phytoestrogens using the FFQ, compared to the $24 \mathrm{~h}$ recall. This may be because the composition of phytoestrogens in certain food items that were consumed in the previous $24 \mathrm{~h}$ were not included in the food database; some phytoestrogens have not been analyzed for particular food components. Since total phytoestrogens consist of the sum of all the individual compounds, the lack of one or more of them contributes to a lower concentration of total phytoestrogens. On the other hand, the FFQ contains a larger list of foods, and many of them may have a complete composition of phytoestrogens in the database.

Some authors attribute the weak or null association of individual compounds to the extensive response categories used in the FFQ, and imprecise interpretation of the interviewer to describe "a few times a week" or "daily or almost daily" [30]. Additionally, composition tables used are not representative of the foods that were consumed. Thus, dietary intake data in our study were based on estimated values and were therefore less accurate than intakes measured by urinary concentrations.

The information available on the dietary intake of phytoestrogens in the general population in Western countries is limited. The estimated habitual $(3.2 \mathrm{mg} /$ day) and recent $(1.4 \mathrm{mg} /$ day $)$ intakes of isoflavones in women of our study were higher than those reported in previous studies. In postmenopausal White women who participated in the Framingham study, with less than $1 \mathrm{mg} / \mathrm{d}$ of isoflavone intakes [31]. Women who participated as controls in a study of ovarian cancer, consumed in average $1.8 \mathrm{mg} /$ day of isoflavones [32], similar to our participants.

Compared to Asian women [33], mean consumption of isoflavones in our study was approximately 8 times smaller. In terms of total lignans and coumestrol, our results from the FFQ were similar to the $1 \mathrm{mg} /$ day and $1.4 \mathrm{mg} /$ day, found in the Bandera et al. study [32]. Naringenin and quercetin were the most consumed flavonoids in our study and their main dietary sources were citrus fruits and onion, respectively.

Overall, our results indicate that the intake of dietary isoflavones exceeded consumption of lignans, which is contrary to the results reported by previous studies in Western diets $[34,35]$. This discrepancy could be due to the use of more individual phytoestrogens that were added for the assessment by group. Another reason could be the continuous use of soy protein, soy isolated, and soy flour as food additives in the manufacture of soy-based cereal, frozen desserts, energy bars, and particularly meat substitutes [36]. The FFQ included foods such as "Maizoro" cereal, commercial bread, breading, instant soups, and soy beverages, among others, that contributed to the estimates of isoflavone intakes.

Some studies have evaluated the relationship between estimates of dietary intake and urinary excretion of lignans. As in our study, in Australian women, no association between habitual lignan excretion and dietary intake was found for the FFQ [37]. This is likely due to the wide variety of foods containing lignans, making estimations of lignan intake a challenge. The lack of analysis of the different types of lignans in the Western diet contributed to the underestimation of dietary lignans intake in our study, using the FFQ. The lignan or isoflavone concentrations can vary in the same food according to location, variety, crop season, and processing methods [38,39]. Therefore, measuring dietary intakes of phytoestrogens using a food-intake instrument and food composition databases is complicated and may not fully capture the intake of these compounds. Establishing a biomarker of phytoestrogen intake through the present study means that dietary intake can be estimated reasonably accurately from analysis of a $12 \mathrm{~h}$ urine collection.

This is the first study on the daily intake of phytoestrogens and their correlation with urinary excretion of these compounds in Mexican women. In a recent study from Northwest Mexico, the authors evaluated the use of serum phytoestrogens as a biomarker of phytoestrogen intake, and found correlations for some individual compounds, such as naringenin, luteolin, genistein, enterolactone, coumestrol, and resveratrol [19]. However, no correlations were found for groups or 
for total phytoestrogens. We found correlations between recent intakes and urinary levels for total phytoestrogens, and for groups of isoflavones, lignans, and flavonoids, as well as for genistein and naringenin as individual compounds.

In a study that evaluated serum and urine as biomarkers of intake of phytoestrogens in the general US population, the authors discussed that the concentrations of phytoestrogens were lower in serum than in urine, which points to the fast clearance of these compounds from the body [40]. The time of the collection of the blood sample is an important variable for the determination of phytoestrogens because of their short half-lives. Isoflavones, in the form of glucuronic, predominate in urine, and half-life is approximately 7 to $10 \mathrm{~h}$ [41]. Enterolignans appear in circulation approximately 8 to $10 \mathrm{~h}$ after the ingestion of lignans derived from plants. In contrast, lignans derived from plants are in blood circulation after $2 \mathrm{~h}$ of consumption but their concentrations are lower than those of enterolignans [42]. Thus, urine collections may be more useful for the complete estimation of lignan and isoflavone levels than blood samples. The authors from the study previously mentioned mentioned that the high correlation observed for urinary and serum levels of phytoestrogens validates that noninvasive collection techniques, such as those used for urine, can be used to assess phytoestrogen exposure [40].

Another study in México estimated the dietary intake of phytoestrogens [18]. The authors applied an adapted FFQ to measure the consumption of flavonoids (flavonols, flavones, and flavanols), lignans (secoisolariciresinol, matairesinol, lariciresinol, and pinoresinol), and coumestrol. Only the intake of coumestrol was similar to that obtained in our study. The same estimations were made in a study of Torres-Sánchez et al. [43]. The differences in the intake of phytoestrogens between these two studies and our research could be due to the fact that they used different food composition databases.

In addition to dietary intake, metabolism by intestinal bacteria can also influence an individual's urinary levels of phytoestrogens, especially equol, which is transformed from daidzein by gut microflora [44]. The concentrations of equol that we found in the urine samples from the participants in our study (median, $23.1 \mathrm{ng} / \mathrm{mL}$ ) were higher than those found in women from Hanoi, Vietnam $(19 \mathrm{ng} / \mathrm{mL})$, and exceeded the values of women in Japan $(1.4 \mathrm{ng} / \mathrm{mL})$ and USA $(2.5 \mathrm{ng} / \mathrm{mL})$ [15]. However, daidzein concentrations were lower in our sample, although we found a significant correlation coefficient between urinary daidzein concentration and its metabolite equol. Diet may contribute to the ability to harbor equol-producing bacteria [45,46]; therefore, not all humans $(30-60 \%)$ possess the gut flora that produces equol [47].

When we estimated concentration ratios of equol to daidzein in urine samples, as an indicator of conversion efficiency, significantly higher ratios were found for our samples (ratio equol/daidzein $=0.61$ ), compared to samples from women in Hanoi, Vietnam (ratio $=0.53$ ), and Japan (ratio $=0.002$ ) [15]. These results indicate a more efficient biotransformation of daidzein into its metabolite equol by the Mexican women in our study. Equol has a higher estrogenic activity when compared to daidzein, and has been proposed as an important component of isoflavones for disease prevention [48]. Biotransformation of daidzein to equol has been proposed as a key factor in the protective effects of phytoestrogens against breast cancer $[49,50]$. Thus, our results indicate that the population in Mexico comprised "good" equol producers, and this phenotype could have epidemiological implications for the reduction of some chronic diseases, such as breast cancer risk.

We also observed that the ratio of enterodiol to enterolactone, which can interconvert, was 0.25 (less than 1), indicating that enterolactone was excreted in higher amounts than enterodiol. This finding is in agreement with other human studies [40,51]. The bacterial synthesis of enterolactone occurs via dehydroxylation and demethylation of matairesinol. Enterolactone is also produced by oxidation of enterodiol, which is a product of secoisolariciresinol metabolism [52]. The biological activity of enterolactone and enterodiol is different; enterolactone is a more potent aromatase inhibitor and has approximately 10 times the estrogenic activity than enterodiol [53]. According to Liu et al. [54], enterodiol and enterolactone both have potent inhibitory effects on ovarian cancer, but enterolactone possesses a more effective anti-cancer capability and fewer side effects than enterodiol. Enterolactone also has inhibitory effects on growth and metastasis in human breast 
cancer [55]. Thus, differences in metabolism and exposure of these lignans may be of physiological importance in cancer prevention.

On the other side, variations between the estimated intake and the urinary levels of individual or group phytoestrogens, especially when we used the FFQ, could be due to the difficulty in estimating phytoestrogen intakes. The FFQ, by definition, is a semiquantitative questionnaire with a trend toward the overestimation of intake. Methods of dietary assessment are estimations of intake and rely on the veracity or reported intakes. Therefore, the accuracy of dietary data is influenced by memory recall, body size, sex, age, and ethnicity, as well as psychosocial and behavioral factors [56-59].

Studies in developing countries have shown that energy intake is underreported [60,61]. In fact, underreporting intake of some foods is apparent in our study, since energy intake from the $24 \mathrm{~h}$ recall was low, $1473 \mathrm{kcal} /$ day. According to Scagliusi et al. [62], individuals with a lower income might have greater difficulties in the reporting tasks. Body mass index is also an important variable. As obesity increases, especially in the female population, underreporting energy intake is more common. Irregular meal habits and low education have been also associated with the under-report of energy intake [63]. In a study in New Zealand, the authors detected 265 unreported foods (often snacks) as revealed by the use of wearable cameras [64].

According to the above, we might think that the under-report of energy intake may be due to the frequency of overweight and obese persons in our study population ( $37.3 \%$ and $38.8 \%$ respectively, according to body mass index). Low income and education are factors that could contribute to the underreporting of energy intakes, since $64 \%$ of women in our study were from a lower-income level and $58.6 \%$ had less than 9 years of schooling. Considering the possibility of the underestimation of intake in our study population, reported consumption of unhealthy foods that are rich in fat, high in sugar, or highly processed may be lower than habitual intake; thus, fruits and vegetables, which represents a source of phytoestrogens, may be overestimated.

A limitation of our study is the use of an FFQ validated for women in the region and modified for the study, although not validated specifically for phytoestrogens. The food list increased in the questionnaire, which could lead to an overestimation of phytoestrogen intake. The collection of $12 \mathrm{~h}$ instead of $24 \mathrm{~h}$ urine may be another limitation of our study. We used $12 \mathrm{~h}$ urine since it is a less burdensome method, and the $24 \mathrm{~h}$ urine collection was not well accepted by potential participants. Therefore, women collected their urine samples during the night, and we picked them up in the early morning. As an argument, we may say that, in the study of Grace et al. [65], a spot urine was sufficient for obtaining good results. Because of unpredictable changes in urine flow during the day and since the synthesis and total elimination of creatinine is constant [66], we adjusted the amount of phytoestrogens in urine to the concentration of creatinine. It is desirable that we could have collected urine samples for one or more days in each season of the year to consider seasonal variations in intakes. This could have allowed us to obtain better correlations between phytoestrogens from urine and dietary phytoestrogens estimated from the FFQ, because they represent the usual diet.

An advantage of using urine analysis could mean that we can avoid cases of omission or the overestimation of intake among participants, as well as the problem of not finding a food in the food database. Our quantification method is sensitive and reflects a change due to exposure, since the technique has high specificity and sensitivity. Therefore, the determination of urine levels provides a more accurate and objective measure of intake. The evaluation of 16 individual phytoestrogens, as well as the fact that there is no other study on this subject in Mexican women, is another advantage of our study. The results of our study could motivate other researchers to validate intakes of specific phytoestrogens.

\section{Conclusions}

In conclusion, this study has shown that the urinary excretion of total phytoestrogens is significantly correlated with habitual dietary intake. In addition, recent intakes of individual, group, and total phytoestrogens were related to their urinary levels. Therefore, phytoestrogens in urine may 
be a useful biomarker for the intake of these compounds. The study has furthermore shown the importance of the inclusion of several different phytoestrogens when using total phytoestrogens as a biomarker for intake. The validity of this approach should be extensively investigated. The production of equol by Mexican women is a new avenue of research. This study provides the basis for future studies that look forward to identifying the role of phytoestrogens in reducing the risk of breast cancer and other chronic diseases in the Mexican population.

Acknowledgments: We appreciate our subjects' participation in this study and the support of Agilent in providing the single quadrupole for mass analysis. Our thanks to the Hazardous Waste Laboratory (Department of Food Sciences), in CIAD, for facilitating the use of HPLC-DAD-MS for the analysis. Funding of this project was provided by Consejo Nacional de Ciencia y Tecnología (CONACYT), Research Grant \#CB-2008-01-106028.

Author Contributions: G.C.-J., M.G.-P., L.L.-C. and A.I.V.-Q. conceived the idea and designed the research; K.M.C.-S., M.S.S.-T., M.R.R.-B., S.A.P.-D., M.M.C.-S. and P.G.-C. performed the experiments; G.C.-J., K.M.C.-S. and J.E.-R. analyzed the data; M.I.O.-V., J.E.-R. and M.L.G.-C. evaluated the results; G.C.-J. and K.M.C.-S. wrote the paper; all authors provided input, and read and approved the final version of this manuscript.

Conflicts of Interest: The authors declare no conflict of interest.

\section{References}

1. Reger, M.K.; Zollinger, T.W.; Liu, Z.; Jones, J.; Zhang, J. Urinary phytoestrogens and cancer, cardiovascular, and all-cause mortality in the continuous National Health and Nutrition Examination Survey. Eur. J. Nutr. 2016, 55, 1029-1040. [CrossRef] [PubMed]

2. Matori, H.; Umar, S.; Nadadur, R.D.; Sharma, S.; Partow-Navid, R.; Afkhami, M.; Amjedi, M.; Eghbali, M. Genistein, a soy phytoestrogen, reverses severe pulmonary hypertension and prevents right heart failure in rats. Hypertension 2012, 60, 425-430. [CrossRef] [PubMed]

3. Shi, L.; Ryan, H.H.; Jones, E.; Simas, T.A.; Lichenstein, A.H.; Sun, Q.; Hayman, L.L. Urinary isoflavone concentrations are inversely associated with cardiometabolic risk markers in pregnant U.S. women. J. Nutr. 2014, 144, 344-351. [CrossRef] [PubMed]

4. Nicastro, H.L.; Mondul, A.M.; Rohrmann, S.; Platz, E.A. Associations between urinary soy isoflavonoids and two inflammatory markers in the United States in 2005-2008. Cancer Causes Control 2013, 24, 1185-1196. [CrossRef] [PubMed]

5. Kuhnle, G.G.; Dell'Aquila, C.; Aspinall, S.M.; Runswick, S.A.; Mulligan, A.A.; Bingham, S.A. Phytoestrogen content of foods of animal origin: Dairy products, eggs, meat, fish, and seafood. J. Agric. Food Chem. 2008, 56, 10099-10104. [CrossRef] [PubMed]

6. USDA Database for the Isoflavone Content of Selected Foods, Release 2.0. U.S. Department of Agriculture, Agricultural Research Service, Nutrient Data Laboratory, 2008. Available online: https:/ /www.ars.usda. gov / ARSUserFiles /80400525/Data/isoflav / Isoflav_R2.pdf (accessed on 14 August 2017).

7. Kuhnle, G.G.; Dell'Aquila, C.; Aspinall, S.M.; Runswick, S.A.; Mulligan, A.A.; Bingham, S.A. Phytoestrogens content of beverages, nuts, seeds, and oils. J. Agric. Food Chem. 2008, 56, 7311-7315. [CrossRef] [PubMed]

8. Franke, A.A.; Custer, L.J.; Cerna, C.M.; Narala, K. Rapid HPLC analysis of dietary phytoestrogens from legumes and from human urine. Proc. Soc. Exp. Biol. Med. 1995, 208, 18-26. [CrossRef] [PubMed]

9. Zamora-Ros, R.; Andres-Lacueva, C.; Lamuela-Raventós, R.M.; Berenguer, T.; Jakszyn, P.; Martínez, C.; Sánchez, M.J.; Navarro, C.; Chirlaque, M.D.; Tormo, M.J.; et al. Concentrations of resveratrol and derivatives in foods and estimation of dietary intake in a Spanish population: European Prospective Investigation into Cancer and Nutrition (EPIC)-Spain cohort. Br. J. Nutr. 2008, 100, 188-196. [CrossRef] [PubMed]

10. Wild, C.; Andersson, C.; O'Brien, N.; Wilson, L.; Woods, J. A critical evaluation of the application of biomarkers in epidemiological studies on diet and health. Br. J. Nutr. 2001, 86, S37-S53. [CrossRef] [PubMed]

11. Setchell, K. Phytoestrogens: The biochemistry, physiology, and implications for human health of soy isoflavones. Am. J. Clin. Nutr. 1998, 68, 1333S-1346S. [PubMed]

12. Whitten, P.; Patisaul, H. Cross-species and interassay comparisons of phytoestrogen action. Environ. Health Perspect. 2001, 109, 5-20. [CrossRef] [PubMed]

13. Kelly, G.E.; Joannou, G.E.; Reeder, A.Y.; Nelson, C.; Waring, M.A. The variable metabolic response to dietary isoflavones in humans. Proc. Soc. Exp. Biol. Med. 1995, 208, 40-43. [CrossRef] [PubMed] 
14. Lampe, J.W.; Gustafson, D.R.; Hutchins, A.M.; Martini, M.C.; Li, S.; Wahala, K.; Grandits, G.A.; Potter, J.D.; Slavin, J.L. Urinary isoflavonoid and lignan excretion on a Western diet: Relation to soy, vegetable and fruit intake. Cancer Epidemiol. Biomark. Prev. 1999, 8, 699-707.

15. Kunisue, T.; Tanabe, S.; Isobe, T.; Aldous, K.M.; Kannan, K. Profiles of phytoestrogens in human urine from several Asian countries. J. Agric. Food Chem. 2010, 58, 9838-9846. [CrossRef] [PubMed]

16. Hutchins, A.M.; Lampe, J.W.; Martini, M.C.; Campbell, D.R.; Slavin, J.L. Vegetables, fruits and legumes: Effect on urinary isoflavonoid phytoestrogen and lignan excretion. J. Am. Diet. Assoc. 1995, 95, 769-774. [CrossRef]

17. Karr, S.C.; Lampe, J.W.; Hutchins, A.M.; Slavin, J.L. Urinary isoflavonoid excretion in humans is dose dependent at low to moderate levels of soy-protein consumption. Am. J. Clin. Nutr. 1997, 66, 46-51. [PubMed]

18. Galvan-Portillo, M.V.; Wolff, M.S.; Torres-Sánchez, L.E.; López-Cervantes, M.; López-Carrillo, L. Assessing phytochemical intake in a group of Mexican women. Salud. Pública México 2007, 49, 126-131. [CrossRef]

19. Palma-Duran, S.A.; Caire-Juvera, G.; Robles-Burgeño, M.R.; Ortega-Vélez, M.I.; Gutiérrez-Coronado, M.L.; Bermúdez-Almada, M.C.; Chávez-Suárez, K.; Campa-Siqueiros, M.; Grajeda-Cota, P.; Saucedo-Tamayo, M.S.; et al. Serum levels of phytoestrogens as biomarkers of intake in Mexican women. Int. J. Food Sci. Nutr. 2015, 66, 819-825. [CrossRef] [PubMed]

20. Quizán-Plata, T.; Ortega, M.I. Diseño y validación de una herramienta para identificar riesgo dietario en mujeres adultas de bajo ingreso. Nutr. Clin. 2000, 2, 128-135.

21. Horn-Ross, P.L.; Barnes, S.; Lee, M.; Coward, L.; Mandel, J.E.; Koo, J.; John, E.M.; Smith, E.M. Assessing phytoestrogen exposure in epidemiologic studies: Development of a database (United States). Cancer Causes Control 2000, 11, 289-298. [CrossRef] [PubMed]

22. Milder, I.E.; Arts, I.C.; van de Putte, V.; Venema, D.P.; Hollman, P.C. Lignan contents of Dutch plant foods: A database including lariciresinol, pinoresinol, secoisolariciresinol and matairesinol. Br. J. Nutr. 2005, 93, 393-402. [CrossRef] [PubMed]

23. Pillow, P.C.; Duphorne, C.M.; Chang, S.; Contois, J.H.; Strom, S.S.; Spitz, M.R.; Hursting, S.D. Development of a database for assessing dietary phytoestrogen intake. Nutr. Cancer 1999, 33, 3-19. [CrossRef] [PubMed]

24. Thompson, L.U.; Boucher, B.A.; Liu, Z.; Cotterchio, M.; Kreiger, N. Phytoestrogen content of foods consumed in Canada, including isoflavones, lignans, and coumestan. Nutr. Cancer 2006, 54, 184-201. [CrossRef] [PubMed]

25. Atkinson, C.; Skor, H.E.; Fitzgibbons, E.D.; Scholes, D.; Chen, C.; Wähälä, K.; Schwartz, S.M.; Lampe, J.W. Overnight urinary isoflavone excretion in a population of women living in the United States, and its relationship to isoflavone intake. Cancer Epidemiol. Biomark. Prev. 2002, 11, 253-260.

26. Bolca, S.; Wyns, C.; Possemiers, S.; Depypere, H.; De Keukeleire, D.; Bracke, M.; Verstraete, W.; Heyerick, A. Cosupplementation of isoflavones, prenylflavonoids, and lignans alters human exposure to phytoestrogen-derived 17beta-estradiol equivalents. J. Nutr. 2009, 139, 2293-2300. [CrossRef] [PubMed]

27. Wyns, C.; Bolca, S.; De Keukeleire, D.; Heyerick, A. Development of a high-throughput LC/APCI-MS method for the determination of thirteen phytoestrogens including gut microbial metabolites in human urine and serum. J. Chromatogr. B 2010, 878, 949-956. [CrossRef] [PubMed]

28. Willett, W.; Howe, G.; Kushi, L. Adjustment for total energy intake in epidemiologic studies. Am. J. Clin. Nutr. 1997, 65, 1220S-1228S. [PubMed]

29. French, M.R.; Thompson, L.U.; Hawker, G.A. Validation of a phytoestrogen food frequency questionnaire with urinary concentrations of isoflavones and lignan metabolites in premenopausal women. J. Am. Coll. Nutr. 2007, 26, 76-82. [CrossRef] [PubMed]

30. Willett, W.; Lenart, E. Reproducibility and validity of food-frequency questionnaires. In Nutritional Epidemiology, 2nd ed.; Willett, W., Ed.; Oxford University Press: New York, NY, USA, 1998; pp. 101-147.

31. De Kleijn, M.J.J.; van der Schouw, Y.T.; Wilson, P.W.F.; Adlercreutz, H.; Mazur, W.; Grobbee, D.E.; Jaques, P.F. Intake of dietary phytoestrogens is low in postmenopausal women in the United States: The Framingham Study. J. Nutr. 2001, 131, 1826-1832. [PubMed]

32. Bandera, E.V.; King, M.; Chandran, U.; Paddock, L.E.; Rodriguez-Rodriguez, L.; Olson, S.H. Phytoestrogen consumption from foods and supplements and epithelial ovarian cancer risk: A population-based case control study. BMC Women's Health 2011, 11, 40. [CrossRef] [PubMed] 
33. Chen, Z.; Zheng, W.; Custer, L.J.; Dai, Q.; Shu, X.O.; Jin, F.; Franke, A.A. Usual dietary consumption of soy foods and its correlation with the excretion rate of isoflavonoids in overnight urine samples among Chinese women in Shanghai. Nutr. Cancer 1999, 33, 82-87. [CrossRef] [PubMed]

34. Hernández-Elizondo, J.; Mariscal-Arcas, M.; Rivas, A.; Feriche, B.; Velasco, J.; Olea-Serrano, F. Estimación de la ingesta de fitoestrógenos en población femenina. Nutr. Hosp. 2009, 24, 445-451. [PubMed]

35. Keinan-Boker, L.; van Der Schouw, Y.T.; Grobbee, D.E.; Peeters, P.H. Dietary phytoestrogens and breast cancer risk. Am. J. Clin. Nutr. 2004, 79, 282-288. [PubMed]

36. Patisaul, H.B.; Jefferson, W. The pros and cons of phytoestrogens. Front. Neuroendocrinol. 2010, 31, 400-419. [CrossRef] [PubMed]

37. Hanna, K.; Eaglesham, G.; Patterson, C.; O’Neill, S.; Rees, K.; Chang, B.C.; Lyons-Wall, P. Usual intake of isoflavonoids and lignans in association with urinary excretion-Evaluation of an Australian dietary tool. Asia Pac. J. Clin. Nutr. 2004, 13, S73.

38. Eldridge, A.C.; Kwolek, W.F. Soybean isoflavones: Effect of environment and variety on composition. J. Agric. Food Chem. 1983, 31, 394-396. [CrossRef] [PubMed]

39. Thompson, L.U.; Rickard, S.W.; Cheung, F.; Kenaschuk, E.O.; Obermeyer, W.R. Variability in anticancer lignan levels in flaxseed. Nutr. Cancer 1997, 27, 26-30. [CrossRef] [PubMed]

40. Valentin-Blassini, L.; Blount, B.C.; Caudill, S.P.; Needham, L.L. Urinary and serum concentrations of seven phytoestrogens in a human reference population subset. J. Exp. Anal. Environ. Epidemiol. 2003, 13, $276-282$. [CrossRef] [PubMed]

41. Setchell, K.D.R.; Brown, N.M.; Desai, P.; Zimmer-Nechemias, L.; Wolfe, B.E.; Brashear, W.T.; Kirschner, A.S.; Cassidy, A.; Heubi, J.E. Bioavailability of pure isoflavones in healthy humans and analysis of commercial soy isoflavone supplements. J. Nutr. 2001, 131, 1362S-1375S. [PubMed]

42. Peñalvo, J.L.; Heinonen, S.M.; Aura, A.M.; Adlercreutz, H. Dietary sesamin is converted to enterolactone in humans. J. Nutr. 2005, 135, 1056-1062. [PubMed]

43. Torres-Sanchez, L.; Galvan-Portillo, M.; Wolff, M.S.; Lopez-Carrillo, L. Dietary consumption of phytochemicals and breast cancer risk in Mexican women. Public Health Nutr. 2009, 12, 825-831. [CrossRef] [PubMed]

44. Hendrich, S. Bioavailability of isoflavones. J. Chromatogr. 2002, 777, 203-210. [CrossRef]

45. Brown, N.M.; Galandi, S.L.; Summer, S.S.; Zhao, X.; Heubi, J.E.; King, E.C.; Setchell, K.D. S-(-)equol production is developmentally regulated and related to early diet composition. Nutr. Res. 2014, 34, 401-409. [CrossRef] [PubMed]

46. Wu, X.; Cai, H.; Gao, Y.T.; Dai, Q.; Li, H.; Cai, Q.; Yang, G.; Franke, A.A.; Zheng, W.; Shu, X.O. Correlations of urinary phytoestrogen excretion with lifestyle factors and dietary intakes among middle-aged and elderly Chinese women. Int. J. Mol. Epidemiol. Genet. 2012, 3, 18-29. [PubMed]

47. Franke, A.A.; Halm, B.M.; Kakazu, K.; Li, X.; Custer, L.J. Phytoestrogenic isoflavonoids in epidemiologic and clinical research. Drug Test. Anal. 2009, 1, 14-21. [CrossRef] [PubMed]

48. Bolca, S.; Possemiers, S.; Herregat, A.; Huybrechts, I.; Heyerick, A.; De Vriese, S.; Verbruggen, M.; Depypere, H.; De Keukeleire, D.; Bracke, M.; et al. Microbial and dietary factors are associated with the equol producer phenotype in healthy postmenopausal women. J. Nutr. 2007, 137, 2242-2246. [PubMed]

49. Setchell, K.D.R.; Brown, N.M.; Lydeking-Olsen, E. The clinical importance of the metabolite equol-A clue to the effectiveness of soy and its isoflavones. J. Nutr. 2002, 132, 3577-3584. [PubMed]

50. Ingram, D.; Sanders, K.; Kolybaba, M.; Lopez, D. Case-control study of phyto-oestrogens and breast cancer. Lancet 1997, 350, 990-994. [CrossRef]

51. Kirkman, L.M.; Lampe, J.W.; Campbell, D.R.; Martini, M.C.; Slavin, J.L. Urinary lignan and isoflavonoid excretion in men and women consuming vegetable and soy Diets. Nutr. Cancer 1995, 24, 1-12. [CrossRef] [PubMed]

52. Boriello, S.P.; Setchell, K.D.R.; Axelson, M.; Lawson, A.M. Production and metabolism of lignans by the human faecal flora. J. Appl. Bacteriol. 1985, 58, 37-43. [CrossRef]

53. Wang, C.; Mäkelä, T.; Hase, T.; Adlercreutz, H.; Kurzer, M.S. Lignans and flavonoids inhibit aromatase enzyme in human preadipocytes. J. Steroid Biochem. Mol. Biol. 1994, 50, 205-212. [CrossRef]

54. Liu, H.; Liu, J.; Wang, S.; Zeng, Z.; Li, T.; Liu, Y.; Mastriani, E.; Li, Q.H.; Bao, H.X.; Zhou, Y.J.; et al. Enterolactone has stronger effects than enterodiol on ovarian cáncer. J. Ovarian Res. 2017, 10, 49. [CrossRef] [PubMed] 
55. Xiong, X.Y.; Hu, X.J.; Li, Y.; Liu, C.M. Inhibitory effects of enterolactone on growth and metastasis in human breast cancer. Nutr. Cancer 2015, 67, 1324-1332. [CrossRef] [PubMed]

56. Maurer, J.; Taren, D.L.; Teixeira, P.J.; Thomson, C.A.; Lohman, T.G.; Going, S.B.; Houtkooper, L.B. The psychosocial and behavioral characteristics related to energy misreporting. Nutr. Rev. 2006, 64, 53-66. [CrossRef] [PubMed]

57. Pikholz, C.; Swinburn, B.; Metcalf, P. Under-reporting of energy intake in the 1997 National Nutrition Survey. N. Z. Med. J. 2004, 117, U1079. [PubMed]

58. Johansson, L.; Solvoll, K.; Bjørneboe, G.-E.; Drevon, C.A. Under and overreporting of energy intake related to weight status and lifestyle in a nationwide sample. Am. J. Clin. Nutr. 1998, 68, 266-274. [PubMed]

59. Lichtman, S.W.; Pisarska, K.; Berman, E.R.; Pestone, M.; Dowling, H.; Offenbacher, E.; Weisel, H.; Heshka, S.; Matthews, D.E.; Heymsfield, S.B. Discrepancy between self-reported and actual caloric intake and exercise in obese subjects. N. Engl. J. Med. 1992, 327, 1893-1898. [CrossRef] [PubMed]

60. Ferriolli, E.; Pfrimer, K.; Moriguti, J.C.; Lima, N.K.; Moriguti, E.K.; Formighieri, P.F.; Scagliusi, F.B.; Marchini, J.S. Under-reporting of food intake is frequent among Brazilian free-living older persons: A doubly labelled water study. Rapid Commun. Mass Spectrom. 2010, 15, 506-510. [CrossRef] [PubMed]

61. Abbot, J.M.; Thomson, C.A.; Ranger-Moore, J.; Teixeira, P.J.; Lohman, T.G.; Taren, D.L.; Cussler, E.; Going, S.B.; Houtkooper, L.B. Psychosocial and behavioral profile and predictors of self-reported energy underreporting in obese middle-aged women. J. Am. Diet. Assoc. 2008, 108, 114-119. [CrossRef] [PubMed]

62. Scagliusi, F.; Ferriolli, E.; Pfrimer, K.; Laureano, C.; Cunha, C.; Gualano, B.; Lourenco, B.; Lancha, A. Characteristics of women who frequently under report their energy intake: A doubly labelled water study. Eur. J. Clin. Nutr. 2009, 63, 1192-1199. [CrossRef] [PubMed]

63. Lopes, T.S.; Luiz, R.R.; Hoffman, D.J.; Ferriolli, E.; Pfrimer, K.; Moura, A.S.; Sichieri, R.; Pereira, R.A. Misreport of energy intake assessed with food records and 24-h recalls compared with total energy expenditure estimated with DLW. Eur. J. Clin. Nutr. 2016, 70, 1259-1264. [CrossRef] [PubMed]

64. Gemming, L.; Rush, E.; Maddison, R.; Doherty, A.; Gant, N.; Utter, J.; Mhurchu, C.N. Wearable cameras can reduce dietary under-reporting: Doubly labelled water validation of a camera-assisted 24 h recall. Br. J. Nutr. 2015, 113, 284-291. [CrossRef] [PubMed]

65. Grace, P.B.; Taylor, J.I.; Low, Y.L.; Luben, R.N.; Mulligan, A.A.; Botting, N.P.; Dowsett, M.; Welch, A.A.; Khaw, K.T.; Wareham, N.J.; et al. Phytoestrogen concentrations in serum and spot urine as biomarkers for dietary phytoestrogen intake and their relation to breast cancer risk in European prospective investigation of cancer and nutrition-norfolk. Cancer Epidemiol. Biomark. Prev. 2004, 13, 698-708.

66. Spierto, F.W.; Hannon, W.H.; Gunter, E.W.; Smith, S.J. Stability of urine creatinine. Clin. Chim. Acta 1997, 264, 227-232. [CrossRef]

(C) 2017 by the authors. Licensee MDPI, Basel, Switzerland. This article is an open access article distributed under the terms and conditions of the Creative Commons Attribution (CC BY) license (http:// creativecommons.org/licenses/by/4.0/). 